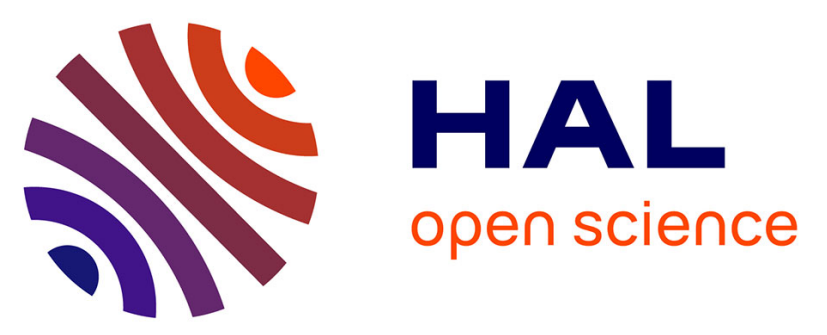

\title{
COSMO, a Bayesian computational model of speech communication: Assessing the role of sensory vs. motor knowledge in speech perception
}

\author{
Marie-Lou Barnaud, Julien Diard, Pierre Bessiere, Jean-Luc Schwartz
}

\section{- To cite this version:}

Marie-Lou Barnaud, Julien Diard, Pierre Bessiere, Jean-Luc Schwartz. COSMO, a Bayesian computational model of speech communication: Assessing the role of sensory vs. motor knowledge in speech perception. ICDL-EpiRob 2015 - 5th International Conference on Development and Learning and on Epigenetic Robotics, Aug 2015, Providence, RI, United States. hal-02004350

\author{
HAL Id: hal-02004350 \\ https://hal.science/hal-02004350
}

Submitted on 1 Feb 2019

HAL is a multi-disciplinary open access archive for the deposit and dissemination of scientific research documents, whether they are published or not. The documents may come from teaching and research institutions in France or abroad, or from public or private research centers.
L'archive ouverte pluridisciplinaire HAL, est destinée au dépôt et à la diffusion de documents scientifiques de niveau recherche, publiés ou non, émanant des établissements d'enseignement et de recherche français ou étrangers, des laboratoires publics ou privés. 


\section{Modeling the concurrent development of speech}

Marie-Lou Barnaud ${ }^{1}$, Julien Diard ${ }^{2}$, Pierre Bessière ${ }^{3}$, Jean-Luc Schwartz ${ }^{1}$

It is widely accepted that both auditory and motor representations intervene in the perceptual processing of speech units. However, the question of the functional role of each of these systems remains seldom addressed and poorly understood.

This is where computational models can play a crucial role. We developed COSMO, a Bayesian model comparing sensory and motor processes in the form of probability distributions which enable both theoretical developments and quantitative simulations.
The three trends about the invariants of speech perception Auditory theories: the invariants are acoustic properties.

Motor theories: the invariants are the intended phonetic gestures of the speaker.

Perceptuo-motor theories: the invariants are perceptuo-motor units

characterized by both their articulatory coherence and their perceptual value.

\section{Context and Bayesian model}

\section{Issues}

Question of interest:

Hypothesis:

Why perceptuo-motor units?

The auditory and the motor systems would be complementary.

COSMO: from a model of communication...

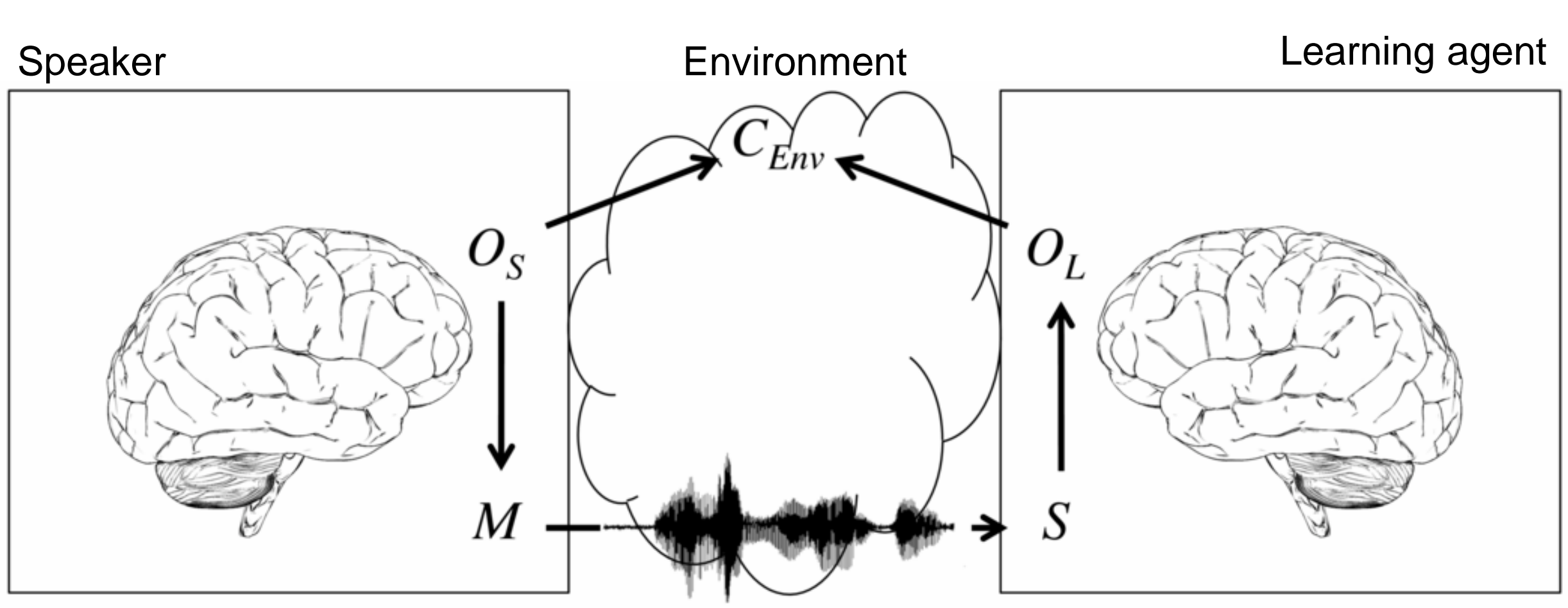

COSMO: ... to a model of communicating agent (the internalization hypothesis)
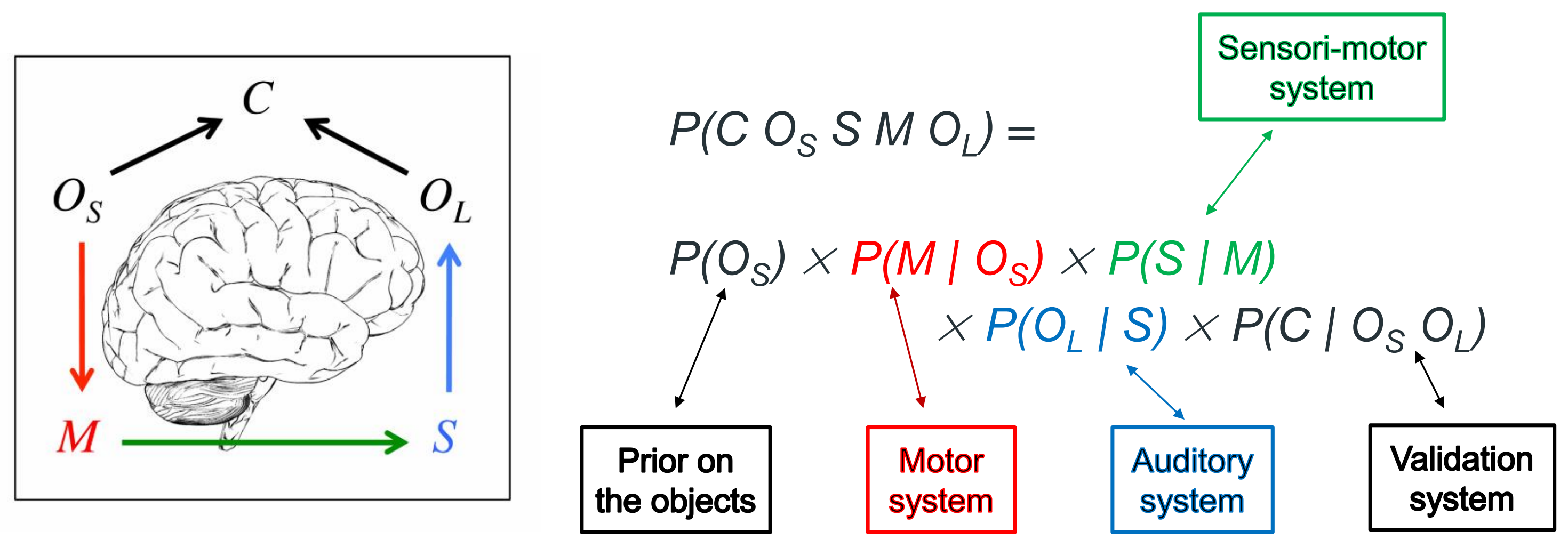

Model learning and simulation of perception processes

Model learning

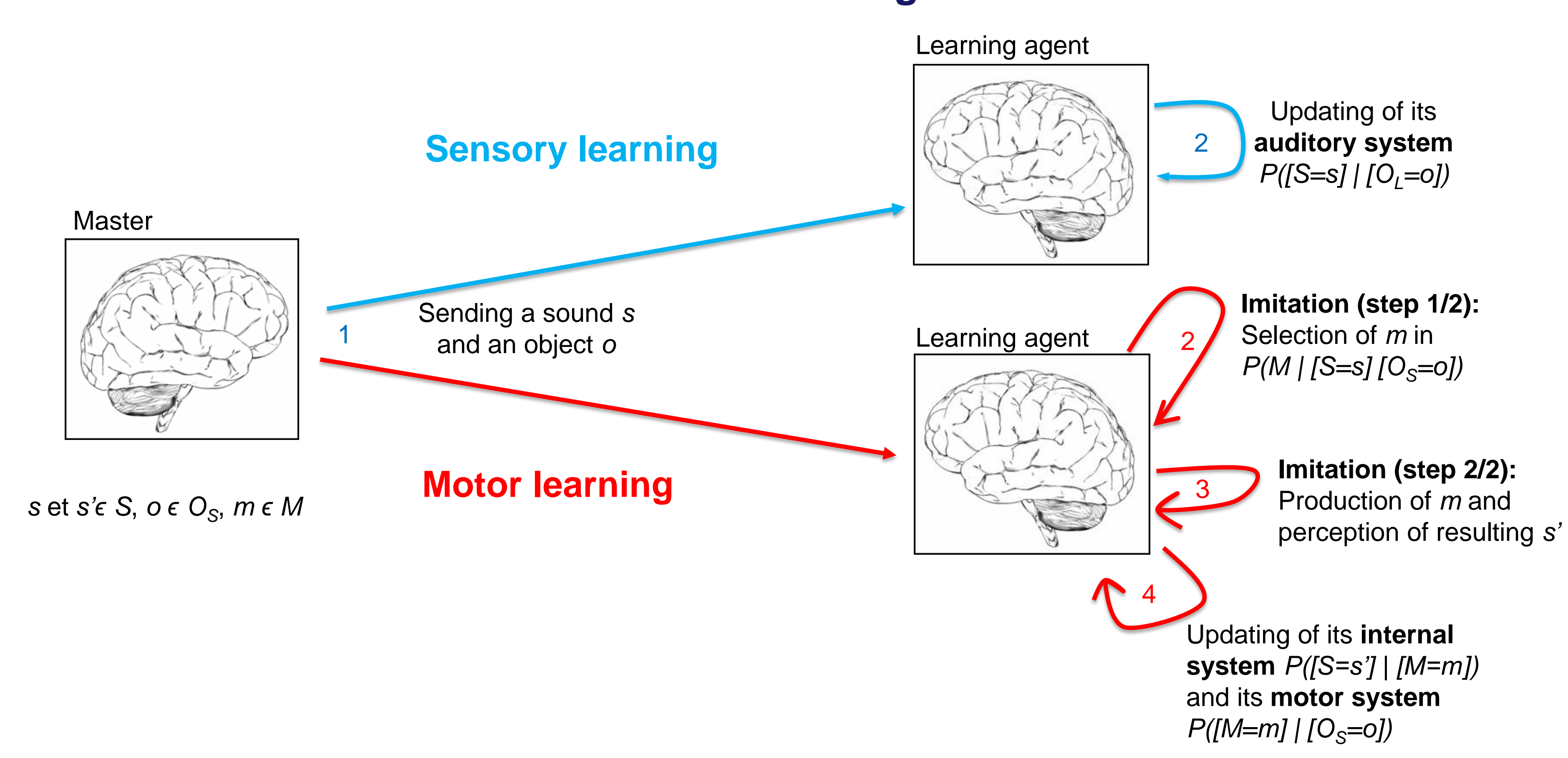

Simulation of perception processes

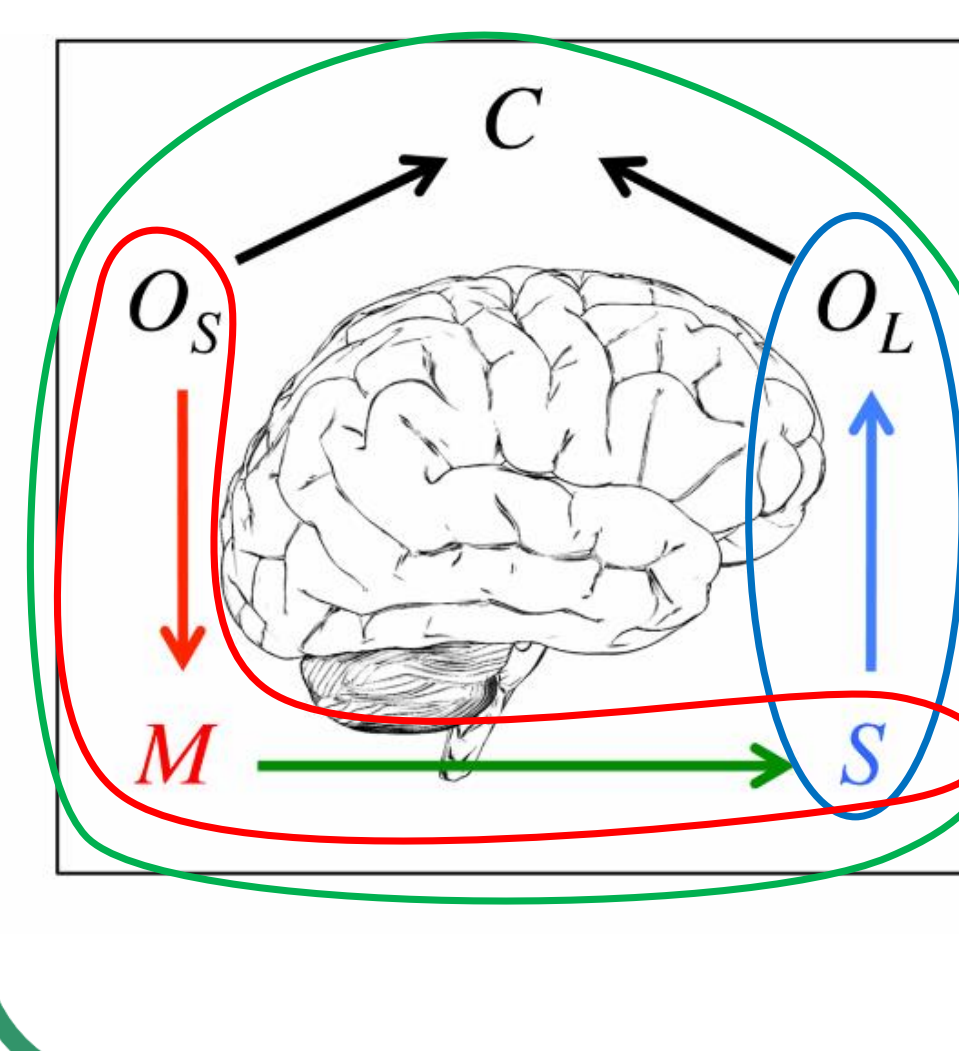

Comparison of three perception processes:

- Sensory system $P\left(O_{L} / S\right)$

- Perceptuo-motor system $P\left(O_{L} O_{s} / S\left[C_{-1} 1\right]\right)$

In 1D simulations:

- 2 objects $O_{1}$ and $O_{2}$

- Spaces $S$ and $M$ in one dimension

- $P\left(M / O_{S}\right), P(S / M)$ and $P\left(O_{L} / S\right)$ gaussians

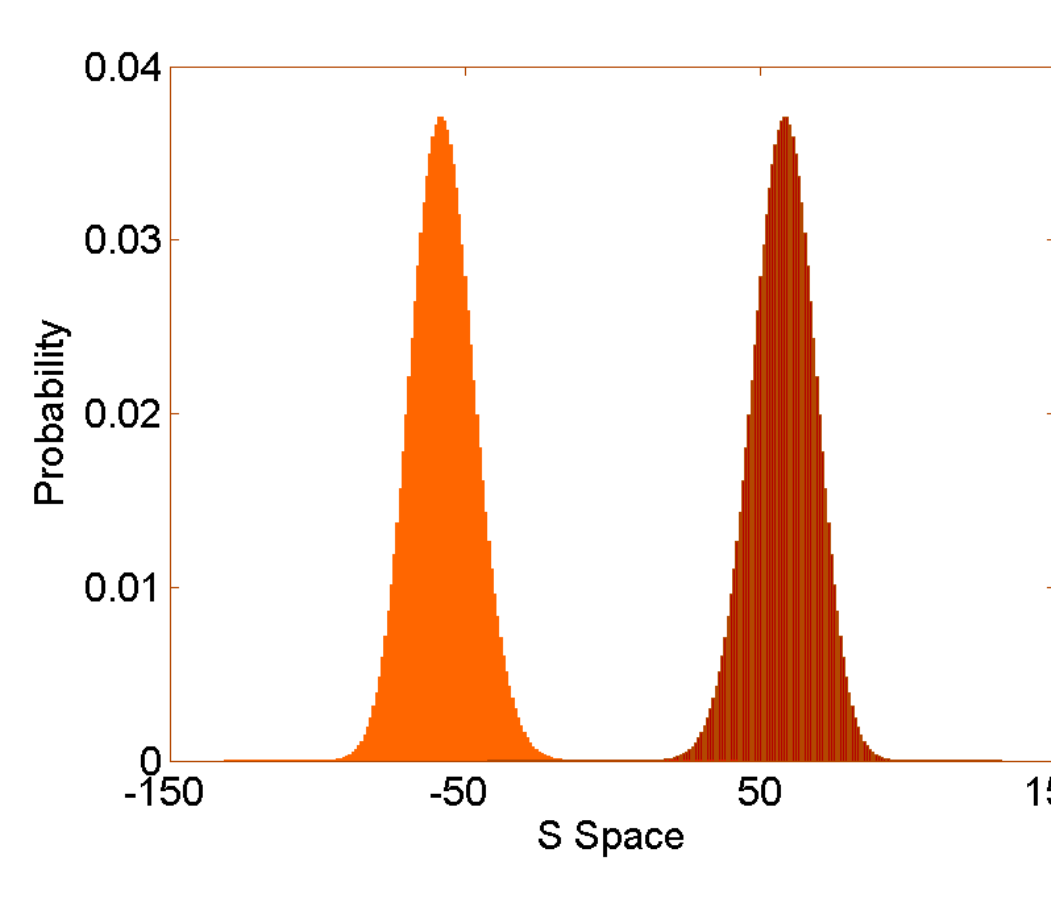

Discussion
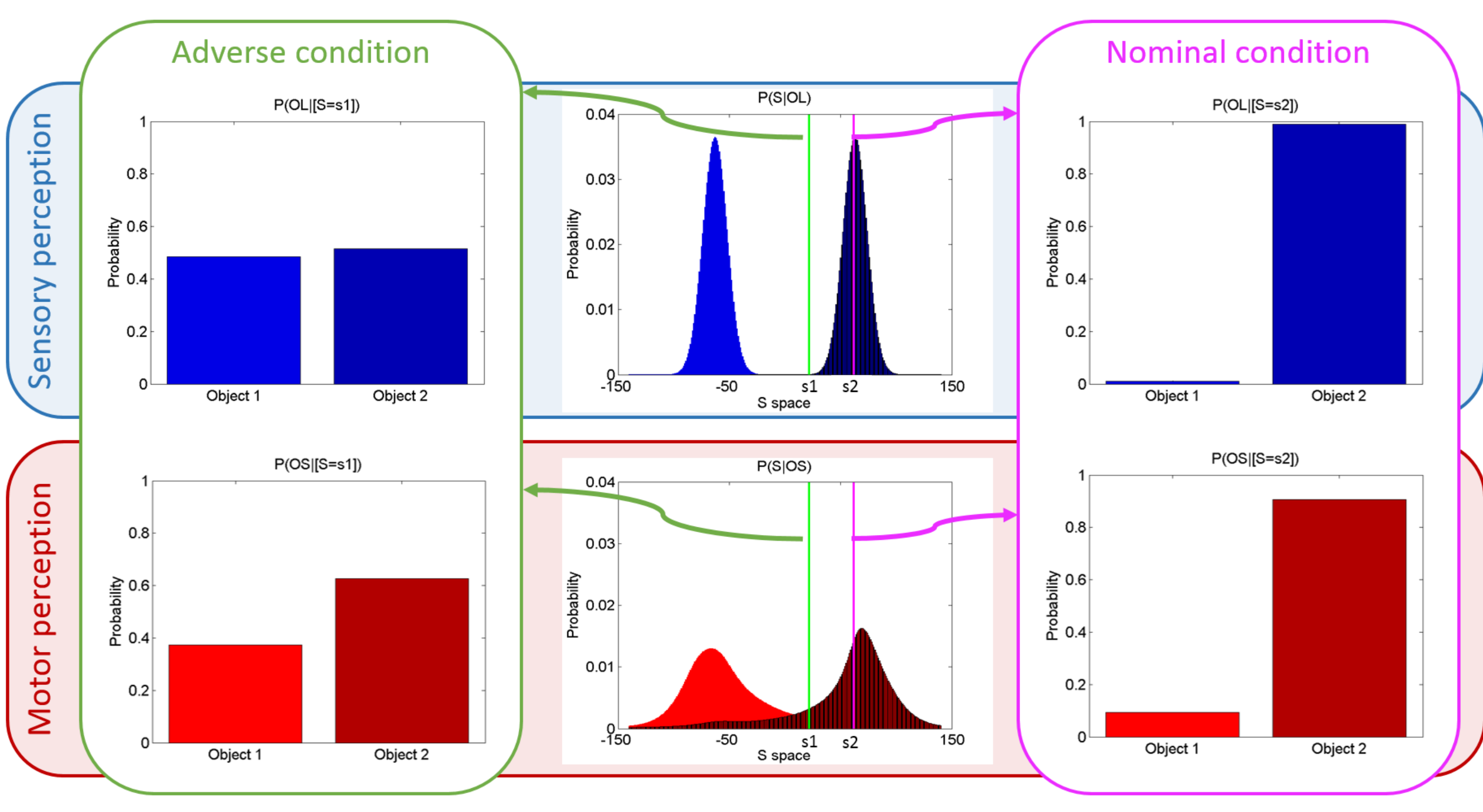

Learning step $=1,000$

The sensory model is of lower variance than the motor model and yields a less uncertain categorization probability distribution than the motor categorization process. By contrast the motor model is of larger variance than the sensory model and generalizes better.

Consequently, in nominal condition, both systems are able to categorize the stimulus but the sensory system is better than the motor system. In adverse condition, the sensory system performs a random categorization whereas the motor system succeeds to correctly categorize.

Conclusion and perspectives

\section{Conclusion}

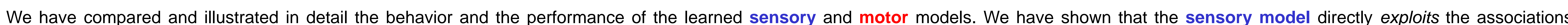

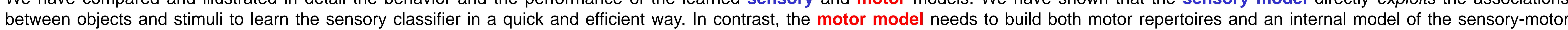

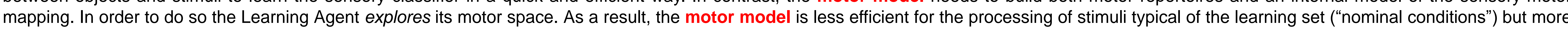

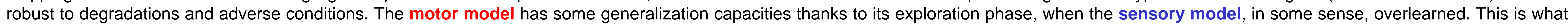
we summarize as the "sensory narrow-band vs. motor wide-band" property.

\section{Perspectives}

- We have already extended COSMO to more complex configurations in multi-dimensional spaces involving synthetic plosive-vowel sequences.

- We are currently exploring further the learning algorithm and its ability to produce "idiosyncrasies" which are variations in learned motor and sensory strategies in the learning agent. 